\title{
Foreword
}

In a work of this brevity it is manifestly impossible to include every theatre built since the Renaissance, or even to discuss every country and the contributions of its architects. For this reason, there are obvious omissions for which I hope I shall be forgiven. The theatres of the Orient are omitted entirely. The theatre in Spain is barely mentioned, and the Spanish popular theatre not at all. In other areas, famous playhouses are passed over completely because they are of little architectural interest or influence. Some theatres are included only because they are representative of a type, others because they are particularly well documented, and still others because they have been the subject of so much interest that their omission would reduce the value of this book. Since the purpose of the book is evaluative as well as historical, I intrude my own opinions and interpretations on occasions when I believe them to be pertinent. A mere list of playhouses has been avoided as much as possible, as have listings of statistics, except on the occasions where these may be of particular interest or relevance.

Illustration and comment has been restricted to permanent theatres, except for a few seminal temporary structures of the Renaissance. Some interesting festival, exhibition, and outdoor playhouses have been erected, particularly in the last generation. It was not thought appropriate to include them, however, because they have not yet had an effect on indoor, permanent construction.
Theatres erected for nondramatic purposes have been omitted entirely, because this is a survey of playhouses, not auditoria or stages. The word "playhouse" is interpreted to include buildings for dramatic entertainment, whether this be spoken drama, vaudeville, opera, or dance. Theatre project plans over the centuries have been influential in the development of new concepts and theories, and no student of theatre architecture can afford to omit them from his study of the subject. Projects have been omitted from this work only because of the limitations of space. Many are, however, listed in the Bibliography of Sources; the student is urged to consult them.

Since the ancient theatre is extremely well documented, and reconstructions are based upon the painstaking observations of archeologists, I have thought it unnecessary to repeat those observations. This volume begins with the Renaissance, because the theatre of that period still is not entirely understood, and because some controversy still exists over the merits of the theatres designed during that time. Detailed observations are presented as much as is practicable, widening into generalizations in later centuries as the number of theatres increases beyond a manageable figure. No attempt is made to give all the historical details about each period, much less about each theatre. Comment about modern theatres has been kept to a minimum, partly through space limitations, and partly because 
such information is readily available, even in modest libraries. This book is designed to supplement studies in theatre history for the student, and to give a clear, generalized portrait of past playhouses to the general reader. I regret that the limitations inherent in such a survey prevent the detailed observations in depth which would be of use to the specialist.

Every effort has been made to present correct data on each of the theatres mentioned. Dates, where given, and unless otherwise qualified, refer to the year of the theatre's opening and not to the year of the laying of the foundation stone, as is normal in discussions of architecture. Theatres are referred to as permanent when reference is made to their construction out of per- manent materials (such as brick or stone), and bears no relation to the length of time which they were used.

Theatres do not make drama. Neither, on the other hand, do actors. A play has been defined as a script performed on a stage by actors before an audience. Each of these elements must be present, in spite of those who refer to almost anything which is exciting as "theatrical" or "dramatic." It is hoped that this brief study of playhouses will make the influence and contribution of the physical stage clearer and more relevant to the life of the theatre as we understand it.

\section{University of Guelph} 1969 